\title{
Topology optimization of steering knuckle structure
}

\author{
Saurabh Srivastava ${ }^{1,2}$, Sachin Salunkhe ${ }^{2}$, Sarang Pande P,* $^{\text {, }}$ and Bhavin Kapadiya ${ }^{1}$ \\ ${ }^{1}$ Department of Mechanical Engineering, Marwadi Education Foundation, Rajkot 360003, India \\ 2 Department of Mechanical Engineering, Vel-Tech Rangarajan Dr. Sagunthala R\&D Institute of Science and Technology, \\ Avadi 600 062, Chennai, Tamil Nadu, India
}

Received: 20 April 2019 / Accepted: 2 December 2019

\begin{abstract}
Steering knuckle connects steering system, suspension system and braking system to the chassis. The steering knuckle contributes a significant weight to the total weight of a vehicle. Increasing the efficiency of an automobile without compromising the performances is the major challenge faced by the manufacturers. This paper presents an effective topology optimization of steering knuckle used in a vehicle with the primary objective of minimizing weight. The study on optimization of knuckle is divided into two phases, the first phase involves making of a computer-aided design model of the original steering knuckle and carry out finite element analysis on the knuckle by estimating the loads, which are acting on the component. In the second phase, design optimization of the model of steering knuckle is carried out, and excess material is removed at the region where induced stress is negligible as obtained in finite element analysis assuming standard boundary and loading conditions. The paper describes a research work carried out to optimize structural topology giving the essential details. The methodology may be applied to optimize structural components used in applications where the ratio of desired properties to the cost, generally in terms of weight, is to be optimized. In the case of automobiles, strength to weight ratio has to be maximized. New researchers working in the area will have an understanding of the procedures, and further, the techniques may be applied to design in general.
\end{abstract}

Keywords: Topology optimization / finite element analysis / steering knuckle / weight optimization

\section{Introduction}

Weight is always an essential criterion while designing any vehicle component. The steering knuckle is an essential part of the vehicle, which is connected to the front wheel with the help of a suspension system and chassis. The primary function of steering knuckle is to convert linear motion of the tie rod to the angular motion of stub axle [1]. To design steering knuckle following requirements must be satisfied; it should be strong enough, light in weight and inflexible during its service. It is a challenging task to attain safety standards and emission standards (BS-VI) for lightduty vehicles with our performance requirements [2]. If the designer only concentrates on safety, it makes the system bulky. Emission regulations are violated as the massive system causes more fuel consumption. On the other hand, if the designer concentrates on emission only, then the safety standard is violated. Compromise has to be made to satisfy safety standards and emission regulations by reducing the weight of components without or least compromising functionality. So, as a part of the best possible solution for satisfying both constraints, the topology optimization

\footnotetext{
* e-mail: sarangpande@gmail.com
}

method is used to achieve sets of the objective to solve any topology optimization problem; it is required to specify three parameters which are design variable (density of material), the objective function (weight reduction) and design constraint (volume). To achieve our objective of weight reduction finite element method is used to exclude the maximum amount of material from the body of a component. The goal is to design a knuckle which has an optimum weight.

Topology optimization can be carried out to reduce the weight of the structure without compromising the intended performance. Topology optimization has its application in the automobile sector for lightweight components and fuel efficiency. Topology optimization of steering knuckle of Formula SAE was carried by Mutha et al. [3] with consideration of boundary conditions and loading conditions acting on the component. After optimization by designing and analysis using FEA solver $40.87 \%$ reduction of weight and volume obtained without compromising the initial performance of steering knuckle. Topologically, optimization of control arm is used in an automobile to reduce its weight and performance improvement. Anand et al. [4] have proven to be useful for identifying a range of potential cross-sectional geometries with a wide variety of load and support conditions. The study was conducted 
using the FE software ANSYS and presented stress-plots with optimal topologies for column and beam crosssections. Viqaruddina et al. [5] used Aluminum 7075 T6 as a material of base control arm then applied boundary and loading conditions wherever required using the Optistruct module in HyperWorks to obtain the optimized structure of control arm. Analysis results of optimized control arm show favourable results and weight reduction up to $40 \%$ achieved. M.M Rahman performed finite element modelling and analysis of connecting rod using finite element software. The topology optimization methodology is used to reduce the weight of the connecting rod. After topology optimization, $11.7 \%$ weight reduction achieved [6].

CAD-based interactive structural topology and design optimization system have been developed by Olhoff et al. [7]. Topology optimization results in the uneven surface of boundaries which is to be modified manually according to practical requirements. By drawing a preliminary structure on the top of base topology, the actual shape optimization model is developed. Bochenek et al. [8] used a minimal compliance objective approach to optimize extruded columns with different support constraints (pinned and fixed) and subjected to a transverse distributed load representing buckling in one or two planes. Optimal topologies and their corresponding critical buckling loads were obtained. Through the 3D approach, the study has also demonstrated variations in bending and shear along the length of a column that result in a non-uniform crosssection. Zuberi et al. [9] attempted to overcome the variation issue through the use of an extrusion constraint in the topology optimization applied to beams is explained later in this paper. However, the resulting cross-sections are limited to overly simplistic shapes, which are likely susceptible to local buckling phenomena due to the slender thin webs. Tsavdaridis et al. [10] applied topology optimization techniques in the design of perforated Isection beams. The study implemented a minimal compliance approach to create a unique optimal web configuration. After that, nonlinear FE buckling analyses were performed on short sections of the optimized and cellular beams for comparison. To minimize the fixed initial domain of continuum structure, Bendsoe et al. [11] presented a homogenization method for topology optimization. In this method, topology optimization problems transformed into optimal material distribution problems by assuming a structure full of microvoids, microscopic material properties computed by the homogenization method and optimal topology obtained by the optimization process. In the homogenization method, the density of the material is treated as a design variable, whereas an objective function is to minimize mean compliance, which is equivalent to maximize global stiffness while satisfying the constraints [12]. Yang et al. introduced the density function approach in which the density of the material is taken as the design variable. The relationship between the material properties and density is presented by the suggested approach for the determination of structural topology [13].

The paper aims to reduce the mass of steering knuckles used in vehicles. The topological optimization process is carried out to reduce the mass of existing steering knuckle

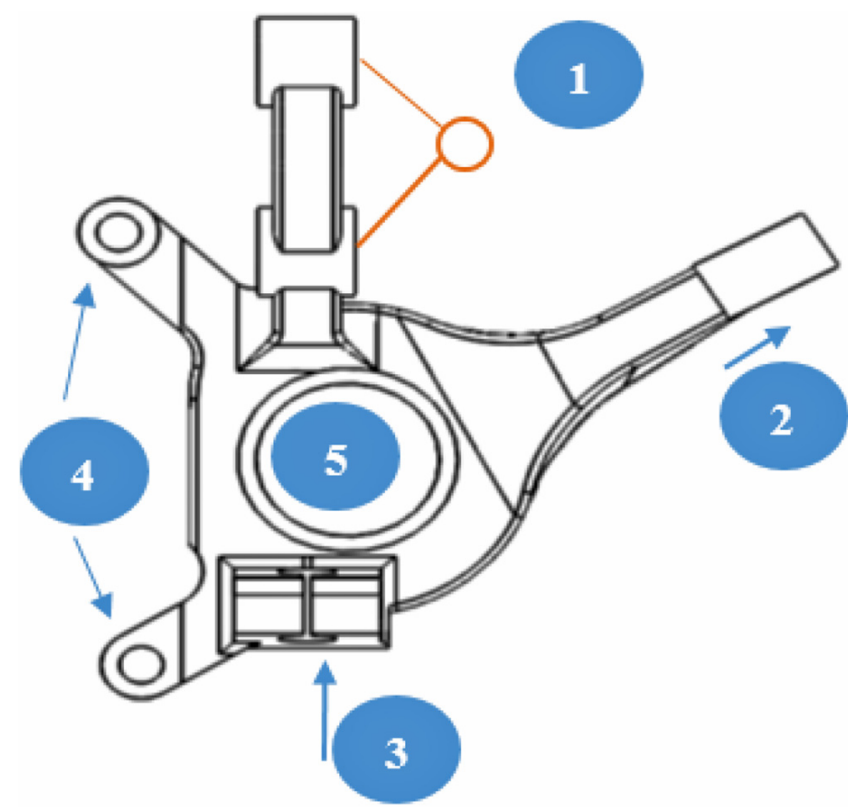

Fig. 1. Connectivity of steering knuckle.

components using finite element analysis [14,15]. After the analysis of the existing steering knuckle, an analysis of the optimized steering knuckle has been done. An iterative process has optimized a CAD model of steering knuckle; in other words, trial and error method, by adding and removing unnecessary material of the initial CAD model of the steering knuckle as topology optimization is a technique for optimum material distribution, material removed at a region where induced stress is negligible and by adding material at the region where induced stress is maximum. After comparing simulation results of the existing steering knuckle and the topologically optimized steering knuckle. The paper deals with the calculation of various forces acting on steering knuckle, modelling and analysis of existing steering knuckle, topologically optimized steering knuckle modelling and analysis after that result comparison at the end of the paper.

\section{Numerical analysis of existing steering knuckle}

\subsection{Computer-aided design modelling}

The CAD model of the steering knuckle, as shown in Figure 1, developed using Solidworks by considering the connectivity of steering knuckle with the hub, lower arm and suspension at rear-drive of the car. Here S.G. iron (ductile iron) material is used, and mass properties are being calculated throughout topology optimization study. A CAD model of steering knuckle is imported in FEM software (ANSYS Workbench) as STEP format for meshing and FEM analysis. Here design study was started with an initial study on existing steering knuckle design. Existing knuckle was made by SG iron, having a mass of about $2.631 \mathrm{~kg}$.

Connectivity of steering knuckle is as follows:

- Suspension mounting-upper arm (strut)

- Tie rod mounting

- Lower arm mounting 
Table 1. Loading conditions [16].

Loading condition on the knuckle

\begin{tabular}{ll}
\hline Breaking force & $1.5 \times \mathrm{m} \times \mathrm{g}$ \\
Lateral Force & $1.5 \times \mathrm{m} \times \mathrm{g}$ \\
Force on knuckle hub in $X$-axis & $3 \times \mathrm{m} \times \mathrm{g}$ \\
Force on knuckle hub in $Y$-axis & $3 \times \mathrm{m} \times \mathrm{g}$ \\
Force on knuckle hub in $Z$-axis & $1 \times \mathrm{m} \times \mathrm{g}$ \\
\hline
\end{tabular}

- Brake calliper mounting

- Stub hole/ball bearing location

\subsection{Loading conditions}

Here, the gross mass of the vehicle (Wagon-R, Maruti Suzuki) is $1340 \mathrm{~kg}$, by considering the mass distribution of 50:50 on the front and rear axle. Here each wheel is sharing an equal amount of mass. The force acting on knuckle was calculated by empirical relations in the form of g-force (gravity force) as shown in Table 1.

Calculation of per wheel mass distribution is as follows: Mass distribution on a wheel $(m)$,

$$
m=M / 4=1340 / 4=335 \mathrm{~kg}
$$

where $M=$ Gross mass of the vehicle.

$$
\begin{aligned}
\text { Force acting on strut } & =1.5 \mathrm{mg} \\
& =1.5(335)(9.81) \\
& =4929.52 \mathrm{~N}
\end{aligned}
$$

Forces acting on knuckle hub can be calculated as,

$$
\text { Force in } \begin{aligned}
x \text {-direction }(F x) & =3 \mathrm{mg} \\
& =3(335)(9.81) \\
& =9859 \mathrm{~N}
\end{aligned}
$$

Hence, Force in $y$-direction $(F y)=9859 \mathrm{~N}$

Force in $\mathrm{z}$ direction $(\mathrm{Fz})=\mathrm{mg}=3286.3 \mathrm{~N}$.

Now, Force on hub

$$
\begin{aligned}
& =\sqrt{F_{x}^{2}+F_{y}^{2}+F_{z}^{2}} \\
& =\sqrt{(9859)^{2}+(9859)^{2}+(3286.3)^{2}} \\
& =14325 N
\end{aligned}
$$

\section{Structural analysis}

Structural analysis of steering knuckle for various loading and boundary conditions was conducted by assuming linear elastic material properties of the steering knuckle. The material properties of SG iron are shown in Table 2 . The finite element model has been created using the tetrahedral element.

For the analysis, forces acting on suspension mounting, hub and lower arm are due to vehicle weight and also forces developed while turning and braking are considered. The
Table 2. Mechanical property of SG iron A536 65-45-12.

\begin{tabular}{ll}
\hline SG Iron A536 65-45-12 & \\
\hline Density & $7100 \mathrm{~kg} / \mathrm{m}^{3}$ \\
Young Modulus & $1.6614 \times 10^{5} \mathrm{MPa}$ \\
Poisson's Ratio & 0.28 \\
Bulk Modulus & $1.2587 \times 10^{5} \mathrm{MPa}$ \\
Shear Modulus & $6.49 \times 10^{4} \mathrm{MPa}$ \\
Yield Strength & $3.1 \times 10^{2} \mathrm{MPa}$ \\
Ultimate tensile strength & $4.48 \times 10^{2} \mathrm{MPa}$ \\
\hline
\end{tabular}

linear analysis of steering knuckle shows that stress concentration is higher in the suspension mounting region (upper arm connection) which is identified as a perilous region of the steering knuckle. From the structural analysis, it has been found that the maximum deflection occurs at suspension mounting and least deflection at the wheel hub centre.

Meshing was done to discretize the design space with the tetrahedron element. Tetrahedron element being one of the standard elements in the Ansys solver is used, which gives more accurate results compared to other elements. The tetrahedron element can approximate the model space without any gap in solid. The gap in the meshing or inappropriate formulation of the mesh gives a less accurate result. The resulting mesh, which was used as the design space, is shown in Figure 2. It is divided into 54695 nodes and 32793 tetrahedron elements. Loads are given on the meshed model, which is shown in Figure 3.

\subsection{Simulation result}

After solving the problem in Ansys Workbench using static structural module until convergence of the results, we obtained results of equivalent stress and total deformation, which is shown in Figures 4 and 5, respectively. In simulation results, stress distribution and deformation are shown in the form of colours from red to blue with a range of 12.97-0.029, respectively, where red regions are highly stressed and deformed in Figures 4 and 5, respectively. It can be observed that deformation is maximum at the suspension mounting, whereas stress is maximum at the root of suspension mounting.

Simulation results show $116.69 \mathrm{MPa}$ of maximum equivalent stress developed in the existing steering knuckle model with a maximum total deformation of $0.2644 \mathrm{~mm}$. Here, the factor of safety comes out to be 2.65 , with a mass of $2.631 \mathrm{~kg}$.

Sensitivity analysis is taken into consideration for the finite element analysis of the knuckle joint, considering that the total forces acting on the knuckle should maintain an equilibrium state such that $\sum \mathrm{F}=0$ in both $X$ and $Y$ direction.

\section{Topology optimization}

Topology optimization is used to accomplish a conceptual design solution that is finished for the efficiency and manufacturability at the conceptual level of project 


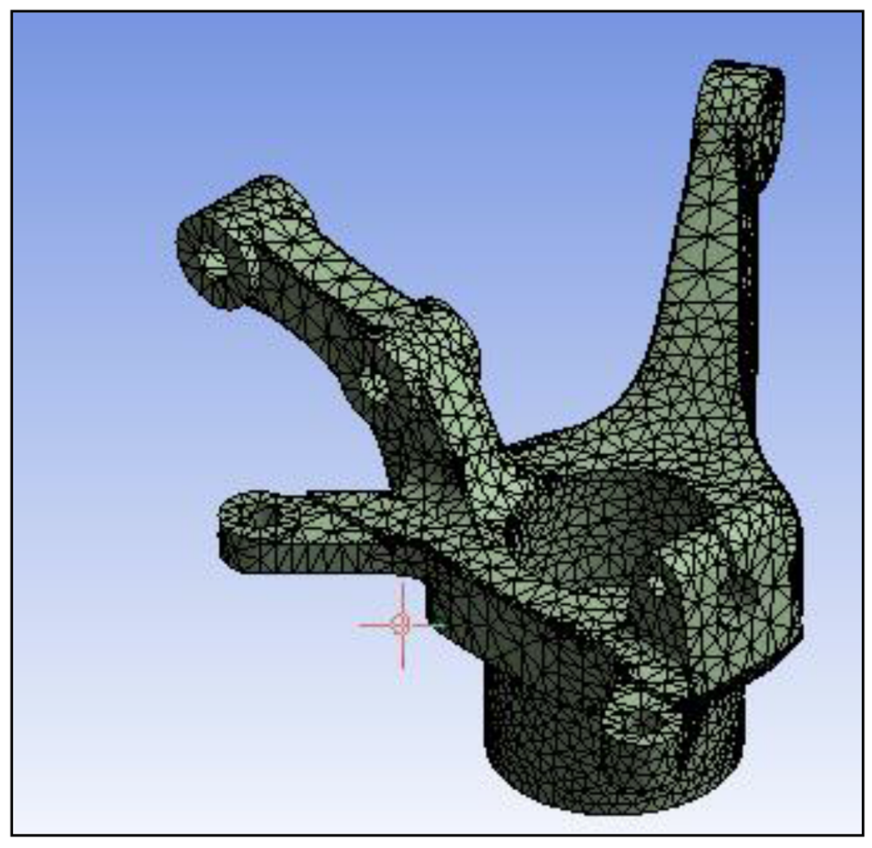

Fig. 2. Meshing.

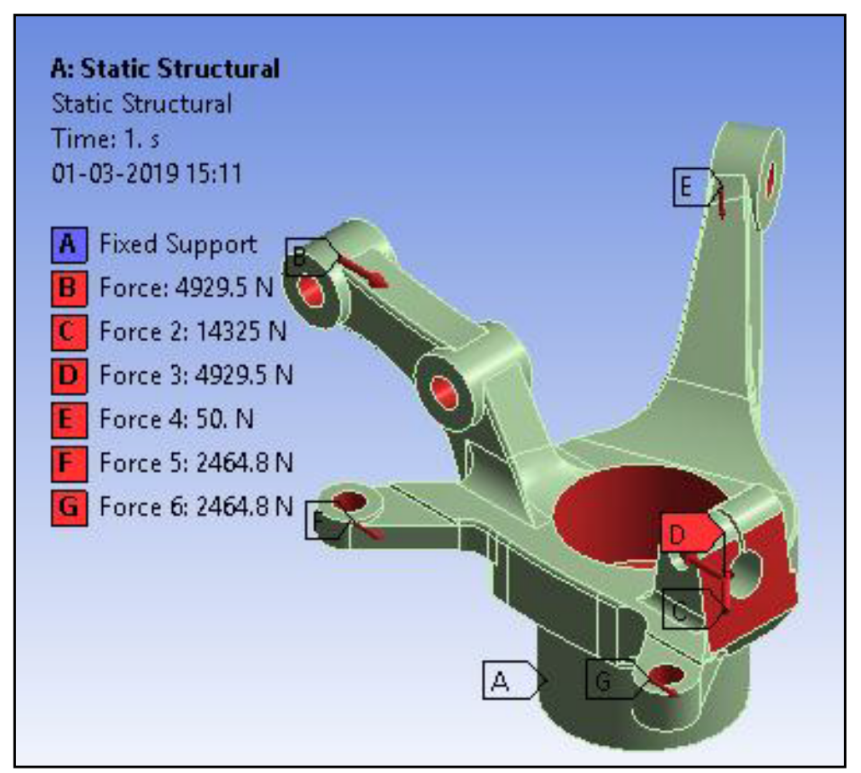

Fig. 3. Applied load on the knuckle.

design creation.

Objective function : $\operatorname{Min} \mathrm{F}(\mathrm{x})$

Subject to $\mathrm{g}(\mathrm{x}) \leq 0$

$\mathrm{h}(\mathrm{x})=0$

Flow chart of topology optimization is shown in Figure 6 .

$x=$ design variable (density)

Objective function $F(x)$ includes function of mass whereas constraints $g(x), h(x)$ includes data of stress and volume.

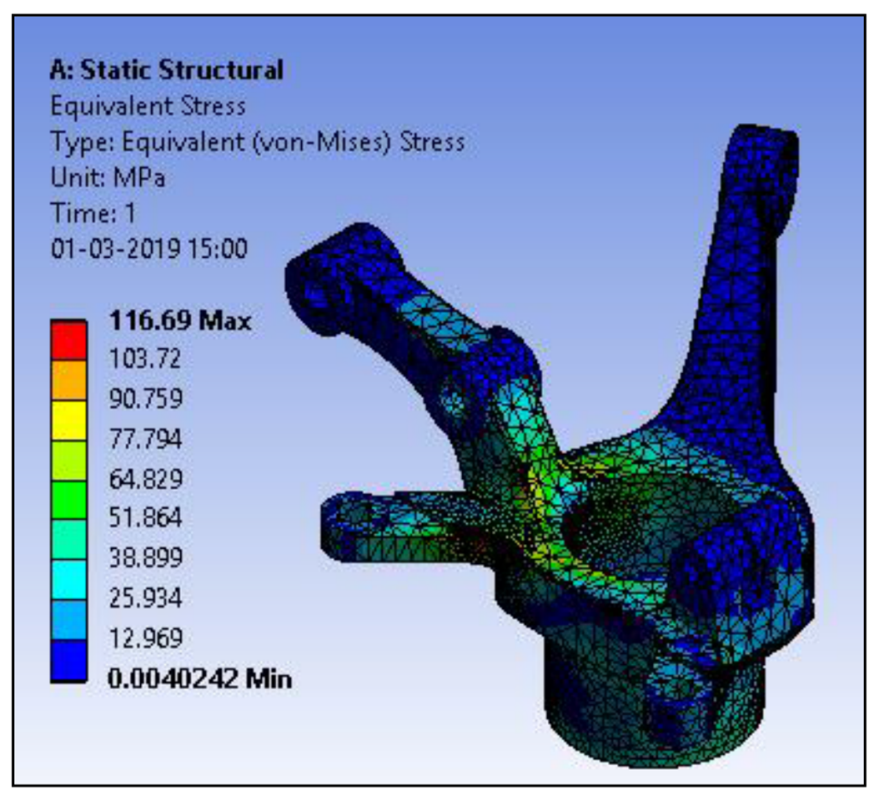

Fig. 4. Equivalent (von-Mises) stress.

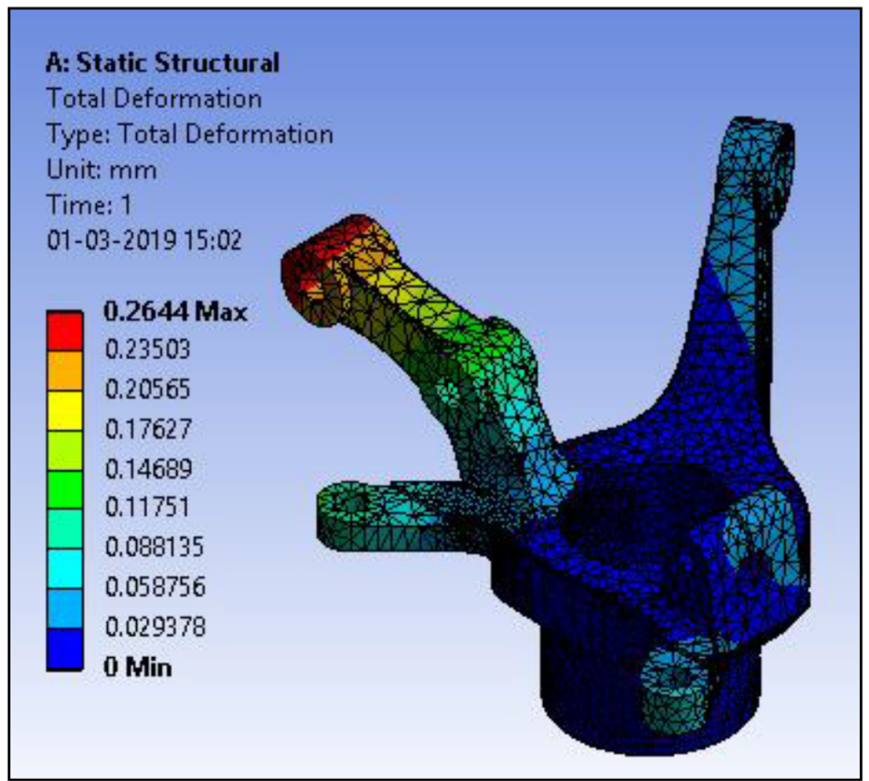

Fig. 5. Total deformation.

There are some categories of structural optimization problems, such as the least mean compliance problem, the maximum natural frequency problem, and the minimum stress problem. In general, the minimum mean compliance problem can be specified as:

$$
\begin{aligned}
& \text { Minimize } J(u, \Omega)=\int_{\Omega} F(u) d \Omega \\
& \text { subject to : } \int_{\Omega} \varepsilon(u)^{T} D \varepsilon(v) d \Omega=\int_{\Omega} p v d \Omega+\int_{\Gamma_{N}} \tau v d \Gamma \\
& u=u_{0} \text { on } \Gamma_{D} \\
& \int_{\Omega} d \Omega \leq \text { vol }
\end{aligned}
$$




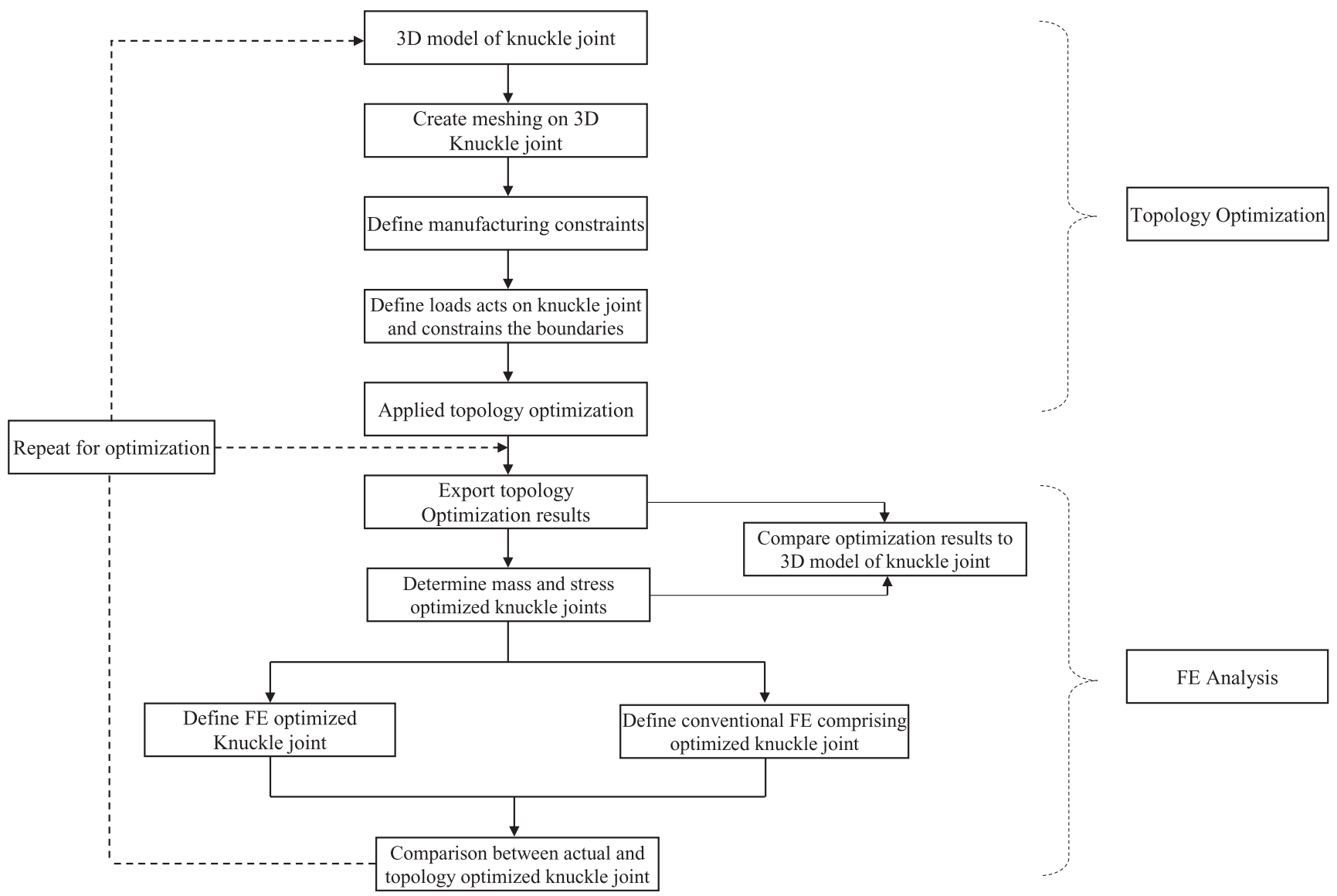

Fig. 6. Topology optimization process.

where $J$, the objective function; $\Omega$, the domain occupied by the structure, $\mathbf{u}$, the displacement vector; $\boldsymbol{\varepsilon}$, strains; $\mathbf{D}$, the elasticity matrix; $\mathbf{p}$, the body forces; $\boldsymbol{\tau}$, the tractions applied on the boundary $\Gamma N ; \mathbf{u}_{0}$, the prescribed displacement on the boundary $\Gamma D ; \mathbf{v}$, the virtual displacements; $\partial \Omega$, the boundary of $\Omega$.

Here, $F(\mathbf{u})$ is strain energy density

$$
F(u)=\varepsilon(u)^{T} D \varepsilon(u) / 2
$$

Inequality (1) defines an upper limit on the amount of material concerning the extreme permissible volume of the structure. A primitive structure of the rectangle is taken to make a new design for the knuckle. Topological optimization is applied to it for fixed boundary conditions at one end. The rectangular structure is considered as a cantilever beam. In Figure 7, topology optimization of a cantilever beam is represented, which is subjected to load at the end and fixed at another end, as shown in Figure 7 (left). Here material was removed where induced stress was found to be negligible and a topologically optimized structure obtained, which is shown in Figure 7 (right).

\section{Numerical analysis of optimized knuckle}

\subsection{CAD model preparation}

The CAD model is created in Solidworks, which is having all connectivity of steering knuckle its braking system, suspension system and steering system. By drawing a preliminary structure on the top of base topology actual shape optimization model is developed as shown in Figure 8. The isometric view and front view of the CAD model is shown in Figure 9. CAD model preparation was done by using a trial and error method. Suspension mounting geometry changed, so the clamp is not required as required in the existing knuckle. Initial design analysis in Ansys is carried out and removed in most of the regions where induced stress concentration is negligible. The final CAD model was prepared and converted to a STEP file for further analysis in Ansys.

Here, meshing was prepared on the created CAD model of topologically optimized knuckle by using the tetrahedron element in Ansys workbench, which fill-up whole design space for further finite element analysis. Meshing was done to discretize the design space with the tetrahedron element. The resulting mesh which was used as the design space is shown in Figure 9, which is discretized into 69905 nodes and 43454 elements. The loads acting on the knuckle is shown in Figure 10.

\subsection{Simulation result}

Finite element analysis was carried out in Ansys workbench by using the static structural module. This analysis was carried out for verification of the compatibility of the optimized knuckle arm. The obtained results of 

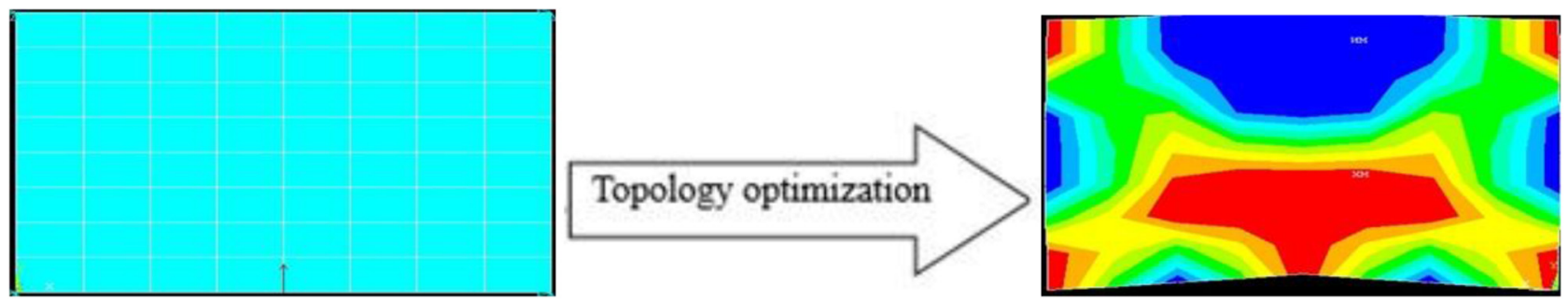

Fig. 7. Topology optimization of beam.
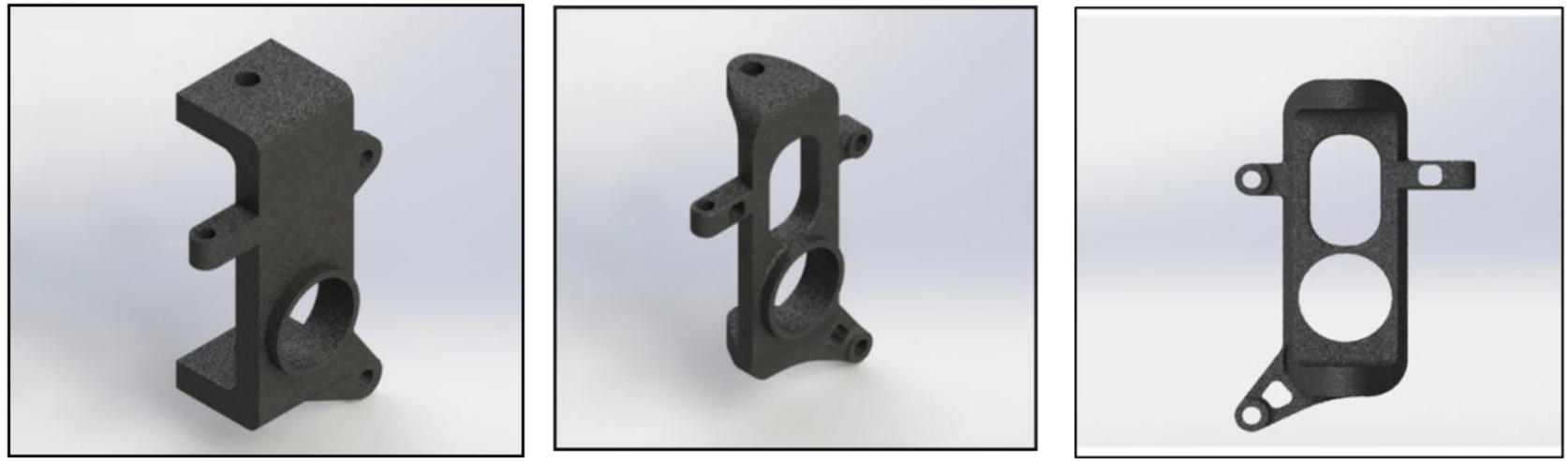

Fig. 8. Views of optimized knuckle.

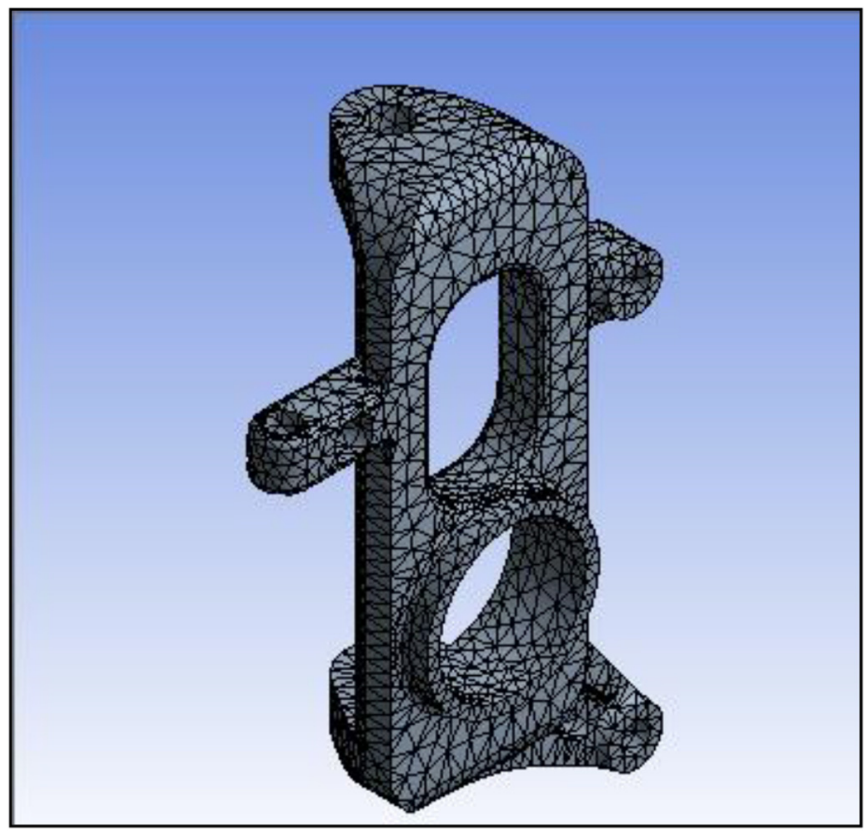

Fig. 9. Meshed model of optimized knuckle.

equivalent stress and total displacement are shown in Figures 11 and 12, respectively. In simulation results, stress distribution and deformation are shown in the form of colours from red to blue, where red regions are highly stressed and deformed in Figure 12. It can be observed that deformation is maximum at the suspension mounting, whereas stress is maximum at the root of brake calliper

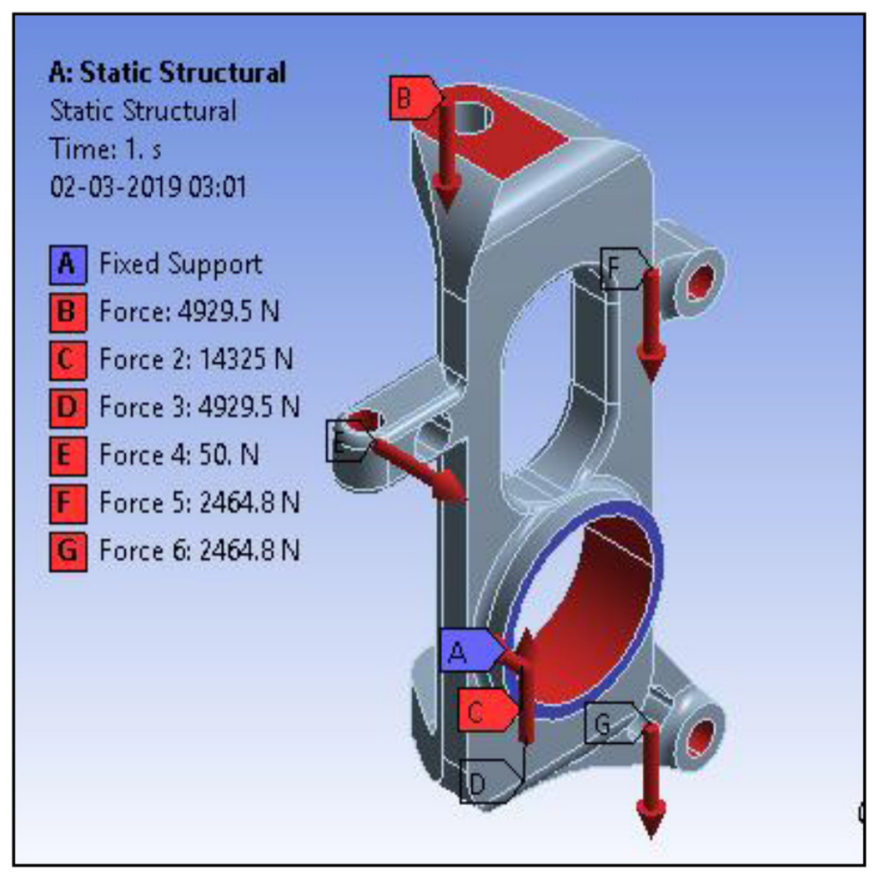

Fig. 10. Loads acting on the optimized knuckle.

mounting. In simulation results, stress distribution and deformation are shown in the form of colours from red to blue region with a range of $13.54-0.029$, respectively, where red regions are highly stressed and deformed in Figure 12. It can be observed that deformation is maximum at the suspension mounting whereas stress is maximum at the root of brake calliper mounting. 


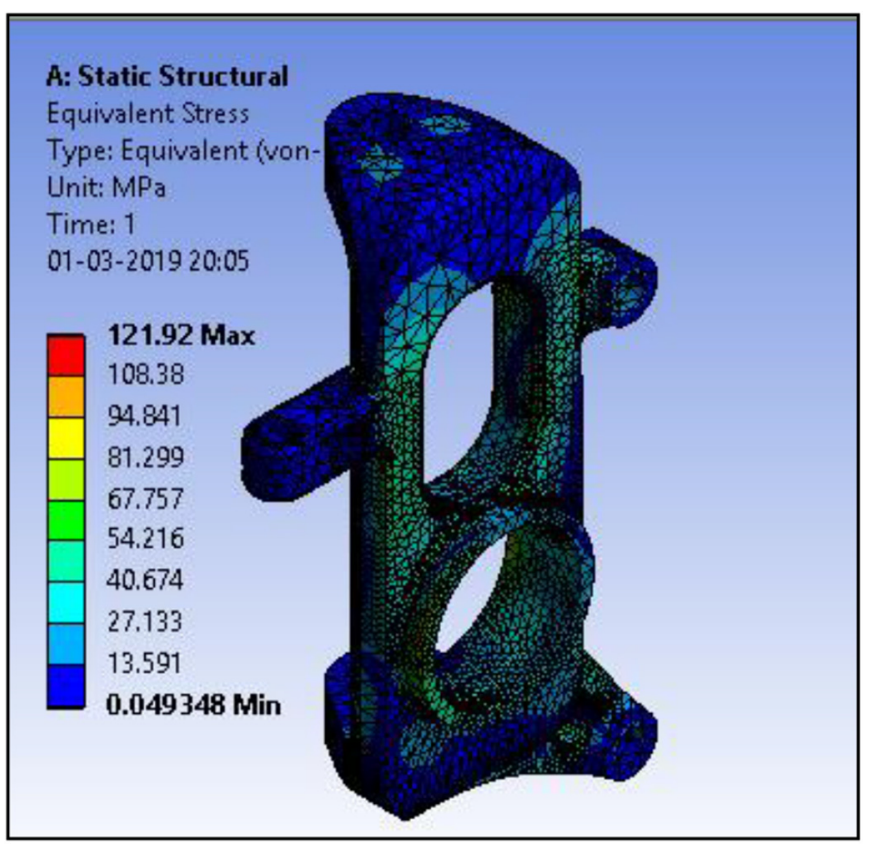

Fig. 11. Equivalent stress.

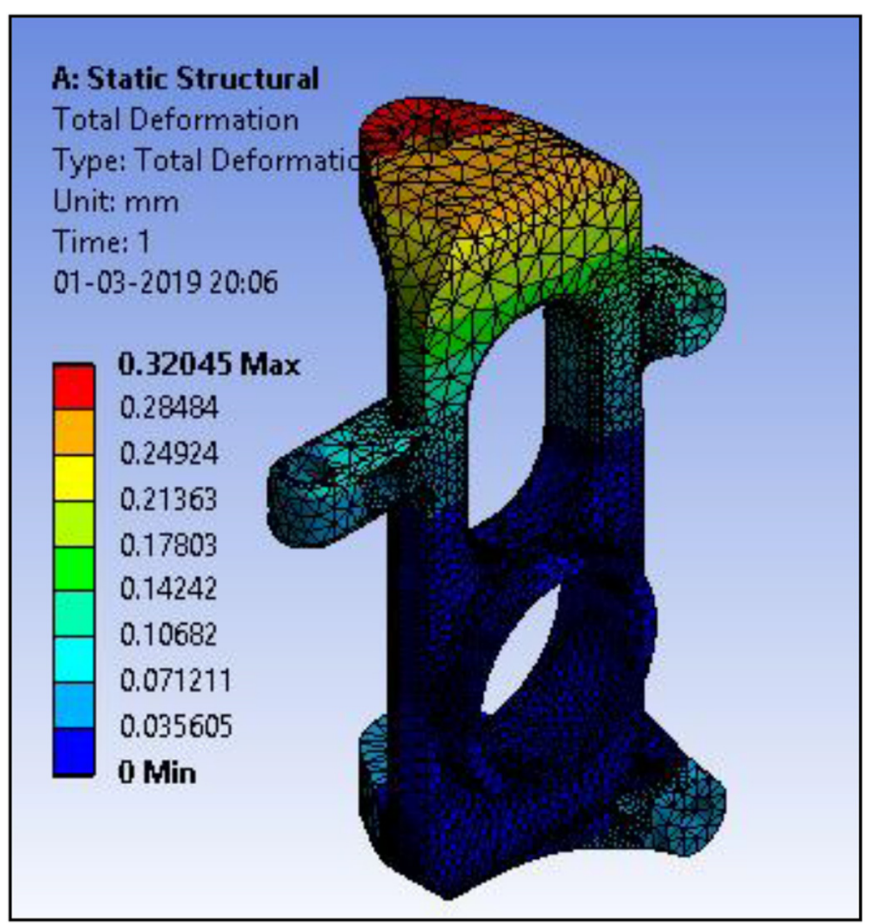

Fig. 12. Total deformation.

Simulation results show $121.92 \mathrm{MPa}$ of maximum equivalent stress developed in an optimized steering knuckle model and maximum total deformation of $0.32045 \mathrm{~mm}$. Here factor of safety comes out to be 2.54 with an optimized mass of $2.1394 \mathrm{~kg}$.

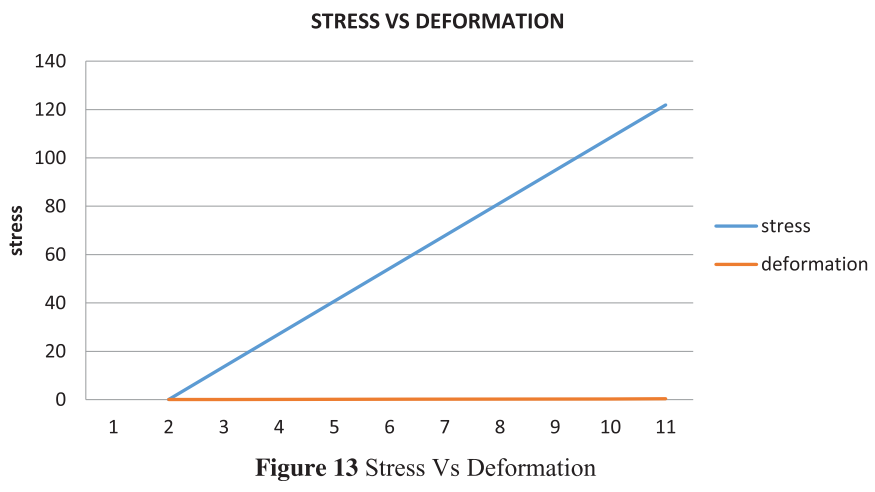

Fig. 13. Stress vs deformation.

Table 3. Comparison of results.

\begin{tabular}{lll}
\hline & Existing knuckle & Optimized knuckle \\
\hline Mass & $2.631 \mathrm{~kg}$ & $2.1394 \mathrm{~kg}$ \\
Deformation & $0.2644 \mathrm{~mm}$ & $0.32045 \mathrm{~mm}$ \\
Stress & $116.69 \mathrm{MPa}$ & $121.92 \mathrm{MPa}$ \\
F.O.S & 2.65 & 2.54 \\
\hline
\end{tabular}

\section{Comparison of results and discussion}

Simulation results show that maximum deformation in original steering knuckle and optimized steering knuckle is at suspension mounting which is $0.2644 \mathrm{~mm}$ and $0.32045 \mathrm{~mm}$, respectively Similarly in the original knuckle, the maximum stress of 116.69 MPa developed at the root of the strut whereas in topologically optimized steering knuckle maximum stress of $121.92 \mathrm{MPa}$ developed at brake mounting, as shown in Figure 13. From the comparison of results of the existing steering knuckle and topologically optimized steering knuckle, it has been found that deformation and induced stress are slightly high in optimized steering knuckle than existing steering knuckle, but it lies in the justified factor of safety. In the process of topology optimization, after topology optimization of the initial CAD model, stress concentration in the model has slightly increased, which results in lowering the factor of safety from 2.65 to 2.54 , which is $4.15 \%$ of the original steering knuckle. Further reduction of mass can be attained by compromising the factor of safety, but in this study factor of safety hasn't been compromised more than $4.15 \%$. This compromise is negligible. The mass of optimized steering knuckle is $0.5 \mathrm{~kg}$ lower than that compared to the existing steering knuckle, and hence, a significant factor of safety and reduced mass design is finalized. The result comparison is shown in Table 3.

\section{Conclusion}

Steering knuckle as a part of the steering mechanism is generally overdesigned. In this study, designing of the knuckle for the steering mechanism is done to provide an 
effective solution with reduced weight. Thus, the overall efficiency of a vehicle is increased. The application of topological optimization is chosen as a tool to design the shape of the knuckle joint, making it lightweight. The obtained results show that topology optimization mass reduction can achieve up to $19 \%$ without compromising its initial performance when compared to the existing design of steering knuckle. A primitive of a rectangular structure is used to apply the topological optimization for weight reduction. The shape of the knuckle is optimized by applying boundary conditions on a rectangular beam. Thus, it is concluded from the study that optimized design is safe as it is having a significant factor of safety. The optimized design of knuckle structure will be used at different positions in an automobile, and then the overall weight reduction of the vehicle gets reduced.

\section{References}

1. V.M. Kumar, Int. J. Adv. Res. Mech. Eng. Technol. 3, 20152018 (2017)

2. Automotive Industry-Standard Committee, The automotive research association of India. Indian emission regulation booklet, 2018

3. A. Mutha, S. Thosar, N. Ghodmare, Innovative Design and Development Practices in Aerospace and Automotive Engineering, Lecture Notes in Mechanical Engineering (Springer, Singapore, 2016)

4. K. Anand, A. Misra, Topology optimization and structural analysis of simple column and short pressurized beams using optimality criterion approach in ANSYS, Int. Res. J. Eng. Technol 2, 1408-1415 (2015)

5. M. Viqaruddin, D. Ramana Reddy, Structural optimization of control arm for weight reduction and improved performance, Mater. Today Proc. 4, 9230-9236 (2017)
6. M. Rahman, M. Shaari, Topology Optimization to Design of Connecting Rod, in 3rd International Conference on Mechanical and Electrical Technology (ICMET-London, 2011), 1-3, pp. $1615-1622$

7. N. Olhoff, J. Rasmussen, M.P. Bendsøe, On CAD-Integrated Structural Topology and Design Optimization, in: Evaluation of Global Bearing Capacities of Structures (Springer, Vienna, 1993), pp. 255-280

8. B. Bochenek, K. Tajs-Zielinska, Minimal compliance topologies for maximal buckling load of columns, Struct. Multidiscipl. Optim. 51, 1149-1157 (2015)

9. R. Zuberi, Z. Zhengxing, L. Kai, Topological optimization of beam cross-section by employing extrusion constraint, in Proceedings of the 12th International Conference on Enhancement and Promotion of Computational Methods in Engineering and Science (EPMESC XII), Macau, 2009

10. K.D. Tsavdaridis, J. Kingman, V. Toropov, Application of structural topology optimization to perforated steel beams, Comput. Struct. 158, 108-123 (2015)

11. M.P. Bendsøe, N. Kikuchi, Generating optimal topologies in structural design using a homogenization method, Comput. Methods Appl. Mech. Eng. 71, 197-224 (1998)

12. C.S. Jog, R.B. Haber, M.P. Bendsøe, A displacement-based topology design method with self-adaptive layered materials, in Topology Design of Structures (Springer, Dordrecht, 1993), pp. 219-238

13. R. Yang, C. Chuang, Optimal topology design using linear programming, Comput. Struct. 52, 265-275 (1994)

14. S.M. Edmund, R. Arora, Design optimization of a three-stage transmission using advanced optimization techniques, Int. J. Simul. Multidiscipl. Des. Optim. 8, 10 (2019)

15. F. Farhatnia, S. Ali Eftekhari, A. Pakzad, S. Oveissi, Optimizing the buckling characteristics and weight of functionally graded circular plates using the multi-objective Pareto archived simulated annealing algorithm (PASA), Int. J. Simul. Multidiscipl. Des. Optim. 14, 10 (2019)

16. S. Yadav, R.K. Mishra, V. Ansari, S.B. Lal, Design and analysis of steering knuckle component, Int. J. Eng. Res. V5, 4 (2016)

Cite this article as: Saurabh Srivastava, Sachin Salunkhe, Sarang Pande, Bhavin Kapadiya, Topology optimization of steering knuckle structure, Int. J. Simul. Multidisci. Des. Optim. 11, 4 (2020) 